\title{
Oral health in the elderly patient and its impact on general well-being: a nonsystematic review
}

\author{
This article was published in the following Dove Press journal: \\ Clinical Interventions in Aging \\ II February 2015 \\ Number of times this article has been viewed
}

José Antonio Gil-Montoya'

Ana Lucia Ferreira de Mello²

Rocío Barrios ${ }^{3}$

Miguel Angel Gonzalez-Moles ${ }^{4}$

Manuel Bravo 3

'Special Care in Dentistry-

Gerodontology Department, Granada

School of Dentistry, Granada, Spain;

${ }^{2}$ Dentistry Department, Federal

University of Santa Catarina,

Florianopolis, Brazil; ${ }^{3}$ Preventive and Oral Public Health Department, Granada School of Dentistry, Granada, Spain; ${ }^{4}$ Oral Medicine Department, Granada School of Dentistry, Granada, Spain
Correspondence: JA Gil-Montoya Facultad de Odontología, Universidad de Granada, Calle: Paseo de Cartuja (sin número), I807I, Granada, Spain Tel +34958243796

Fax +34958243796

Email jagil@ugr.es
Abstract: Data on the oral health of the elderly depict a worrying situation, with an elevated prevalence of caries and moderate periodontal disease, frequent edentulism, and numerous cases of dry mouth and oral cancer. There is wide evidence that periodontitis is a risk factor for certain systemic diseases, and impaired oral health has been associated with mastication and nutritional problems, especially among the elderly, with highly negative effects on their quality of life. In this nonsystematic review, the authors discuss the importance of evaluating the oral health of the geriatric population in a comprehensive manner, beyond simple clinical assessments.

Keywords: oral health, oral health-related quality of life, well-being, elderly

\section{Introduction}

The World Health Organization defined health as a multidimensional construct: "a state of complete physical, psychological, and social well-being and not merely the absence of disease or infirmity", ${ }^{1}$ subsequently describing it in more dynamic terms as "a resource for living" rather than a "state". ${ }^{2}$ This interpretation has led to the development of instruments such as the Health-Related Quality of Life (HRQoL) measure, which refers to the impact of health on individuals' ability to function and their perceived well-being in physical, mental, and social domains. ${ }^{2} \mathrm{HRQ}$ QL is part of a larger concept designated "general well-being" which, according to some authors, is synonymous with "quality of life". ${ }^{2}$ In dentistry, major efforts have been made to develop instruments for the measurement of Oral HRQoL (OHRQoL), ${ }^{3}$ considering the effect of oral health on different aspects of life, including self-esteem, social interaction, and school or work performance, among others. It has been demonstrated that oral health is associated with HRQoL, ${ }^{3}$ finding interrelationships among traditional clinical variables (eg, diagnosis), clinical examination data, and person-centered self-reported health experiences. ${ }^{4}$ Hence, based on the premise that HRQoL affects one's general well-being and that oral health is an integral component of general health, it can be affirmed that oral health is, in part, responsible for the general state of well-being. This is especially important in the elderly. The aim of the present nonsystematic review was to present published data regarding the oral health status of the elderly and its main repercussions, including its impact on general health and nutrition.

\section{Methods}

A comprehensive literature search was conducted, mainly using PubMed and Embase, which was limited to publications written in English over the past 14 years (2000-2014). The following search terms were used: "elderly, aged, or older"; "oral health or oral condition"; "oral health related quality of life"; "health related quality of life"; and "malnutrition". We also searched the Webpages of government health departments, 
international health organizations, consensus reports, and general position statements from scientific societies. These search strategies yielded more than 300 hits. An initial screening process resulted in the exclusion of duplicate articles, conference abstracts, and expert opinions. A final selection of 81 articles was made, including observational and longitudinal studies, systematic reviews, and clinical trials.

\section{Health- and Oral Health-Related Quality of Life}

The relationship between oral health status and general health can be explored from different perspectives, mainly from a subjective viewpoint. Measurement of the HRQoL and OHRQoL, which indicate an individual's level of wellbeing, ${ }^{4}$ is useful to analyze the possible consequences of oral disorders.

HRQoL is a subjective measure of a patient's health in the present and recent past. It has been added to mortality and morbidity as a valid outcome measure, and it has become an important consideration in medical decision making. ${ }^{5}$ HRQoL - ie, the self-perception of general health status is influenced by oral health, and this is especially relevant in the elderly. ${ }^{6}$ Oral problems that frequently affect older populations, such as missing teeth, ${ }^{7}$ dry mouth, ${ }^{8}$ and mastication limitations, were found to be correlated with worse quality of life after controlling for other influences such as general health, income, and marital status. ${ }^{9} \mathrm{OHRQ}$ OL is also influenced by other factors, including socioeconomic status, the regularity of dental visits, treatment-seeking behavior, difficulties in normal daily life activities, and severity of systemic disease. ${ }^{4}$ In general, there is some evidence that poor oral health status in the elderly impairs their self-esteem and social interactions ${ }^{10}$ which, in turn, have a negative effect on their health status and well-being. Indeed, it has been reported that OHRQoL has a positive influence on happiness after controlling for demographic and socioeconomic factors. ${ }^{11}$

Hence, OHRQoL focuses on how oral health affects patients' quality of life, taking into account their self-perception of oral health. OHRQoL is utilized in health service research to examine trends in oral health and to estimate populationbased needs, and it also has important implications for dental research and the clinical practice of dentistry. ${ }^{4}$ Thus, it can be used as a measure of treatment effectiveness, comparing scores before and after interventions (eg, the placement of removable, fixed, or implant-supported prostheses). ${ }^{12}$ OHRQoL can play a key role in clinical decision making as a complement to clinical examination results, especially in the elderly, whose clinical oral health is closely related to subjective and psychosocial aspects. However, an improvement in OHRQoL does not always imply an improvement in HRQoL and well-being, ${ }^{13}$ and dental interventions in the elderly can be difficult and unpredictable. Therefore, account should be taken of the possible consequences of aggressive and complex dental treatments in this age group. The case for measuring "oral health" in terms of quality of life is strong, given that a positive clinical evaluation of the mouth is no guarantee of good oral health status.

At any rate, the results obtained with this type of instrument should be interpreted with caution, especially when applied in the clinical setting. ${ }^{14}$ In the case of both OHRQoL and HRQoL, it is crucial to know whether account is taken of changes in expectations, adaptation, and normalization, and to determine what constitutes an important modification in quality of life, and to whom it is important. ${ }^{15}$ These issues are being addressed in general medicine and must also be resolved in the field of dentistry.

\section{State of oral health in the elderly}

The epidemiological literature on oral health in the elderly is not very encouraging, and it indicates profound imbalances among countries and regions and as a function of institutionalization. ${ }^{16,17}$ This disparity is mainly attributable to differences in socioeconomic conditions and in the availability of and access to oral health services. Most epidemiological questionnaires in this context focus on the 65-74-year age group, and few studies have analyzed individuals over the age of 74 years when oral health falls to worrisome levels of satisfaction. ${ }^{17}$

\section{Dental caries}

Caries remains a major oral health problem among the elderly for various reasons: the increase in treatment and maintenance of teeth rather than their extraction; age-related salivary changes; a poor diet; exposure of the root surface by gingival recession; and a greater likelihood of drug treatment with xerostomia as a side effect. ${ }^{18,19}$ In a study conducted in England, ${ }^{19}$ the prevalence of caries in tooth crowns among the dentate elderly was $22 \%$, with $20 \%$ of $75-84$-year-olds showing active root decay. In general, there is high prevalence of tooth loss due to caries, reflecting the fact that the treatment offered to date has largely been extraction of the affected tooth. The current routine restoration procedure is to remove the least possible amount of decayed tooth and to focus on remineralizing the affected tooth with fluoride, with the aim of improving the quality of life of patients by maintaining their natural teeth and avoiding the need for removable or fixed prostheses. ${ }^{20}$ 


\section{Periodontal disease}

Epidemiological data on periodontal disease (a chronic infectious disease that affects tooth support tissues, including gingiva and alveolar bone) has shown that the most frequent findings among the elderly are the accumulation of bacterial plaque with consequent gingivitis and mild or moderate alveolar bone loss (1.8\% had no signs of periodontal disease and 3.3\% showed severe periodontal lesions). ${ }^{21}$ According to a recent systemic review of studies from 37 countries, ${ }^{22}$ although the incidence of severe periodontitis (greater likelihood of tooth loss) was higher with increasing age, it was low and fairly constant among the elderly.

\section{Edentulism}

When not treated, the final stage of caries and periodontal disease is tooth loss and eventually edentulism, which is highly frequent but represents a failure of the dental care system. Edentulism is directly related to mastication and nutritional problems. Some authors proposed that it may be a good mortality predictor, ${ }^{23,24}$ and others associated it with a substantive quality of life impairment. ${ }^{25}$ Epidemiological data on geriatric populations evidence wide variations in the degree of edentulism among countries, attributable to differences in the utilization of dental services, the provision of public financial support, and/or the implementation of oral health policies.

Complete edentulism has been reported in $21.9 \%$ of over-74-year-olds in the United States ${ }^{26}$ and in $39.6 \%$ of over-74-year-olds in New Zealand, ${ }^{27}$ while in Sweden, the prevalence of edentate patients in this age group decreased from $16 \%$ in 1990 to $7 \%$ in $2000 .{ }^{28}$ Most studies in both developed and developing countries reported a peak in the incidence of severe tooth loss at around 65 years. ${ }^{29}$

Concerned public health authorities in different countries have established various oral health objectives. In Japan, a public health campaign called "Healthy Japan 21 " promoted action to keep 20 or more teeth by the age of 80 years. It fostered collaboration between local health authorities and dental associations to encourage positive oral care for the frail elderly, including the provision of domiciliary dental services. ${ }^{30}$

The problem of edentulism is accentuated when mastication function is not reestablished with dental prostheses. Various studies have determined that a minimum of 20 functional teeth are necessary to guarantee good mastication, although only if they are antagonist pairs. ${ }^{30,31}$ The most prevalent conditions among individuals with prostheses are stomatitis and traumatic ulcer, which can be exacerbated by poor nutrition and unhealthy lifestyles, including poor oral hygiene, excessive alcohol consumption, and tobacco use. ${ }^{16}$ The care, hygiene, and routine dental control of prostheses are essential to avoid oral health-related impediments to well-being.

\section{Dry mouth in the elderly}

The greater life expectancy of populations has also increased the importance of dry mouth as a health issue. ${ }^{16} \mathrm{~A}$ high prevalence of xerostomia and salivary gland hypofunction has been found in vulnerable elderly people. ${ }^{32}$ Etiologic factors include polymedication (especially with antihypertensives, antidepressants, and antipsychotics), ${ }^{33}$ poor general health, female sex, and older age. ${ }^{32,34}$ There have been numerous studies on the impact of dry mouth syndrome on the oral and general quality of life of the elderly because it is one of the problems most frequently reported, and treatment success rates are low. ${ }^{35}$ Various approaches have been studied, including products specifically indicated for dry mouth, such as artificial saliva and saliva-stimulating drugs (pilocarpine), but the outcomes have not been encouraging. ${ }^{36}$ Palliative measures include: rectification of the underlying cause of xerostomia (drugs, diabetes, etc); the avoidance of dry hot environments, dry foods, drugs, alcohol, and smoking, among other situations/activities that may increase dryness; and regular moistening of the mouth with small sips of water, lip balm, or olive oil, among others. ${ }^{36,37}$ Individuals with dry mouth require preventive measures against the consequences of the absence of saliva, including caries, periodontal disease, and candidiasis. ${ }^{37}$

\section{Oral cancer}

Oral cancer represents a major threat to the health of adults and the elderly in both high- and low-income countries. It includes lip, oral cavity, and pharyngeal cancer, and is the eighth most common cancer worldwide. ${ }^{38}$ Incidence and mortality rates are higher in men than in women. The prevalence increases with older age, and oral cancer is of particular concern among over-65-year-olds. Variations among countries are attributable to differences in risk profiles and to the availability of and accessibility to health services, among others. ${ }^{38}$ We highlight its prevalence in south-central Asia and its continuing increase in developed countries. ${ }^{39}$

Oral cancer is frequently treated with surgery, radiotherapy, and/or chemotherapy, and advances have led to a reduction in the mortality rate and to an increased number of survivors. The cancer and its treatment can both be responsible for major anatomical changes in the oral cavity and the alteration of basic functions, including speaking, chewing, 
and/or swallowing, substantially impairing the quality of life of survivors. ${ }^{40}$ A multidisciplinary approach is essential for reducing the impact on patients, with an important role for dentists. Dental care before, during, and after treatment can help to maintain or improve the quality of life of oral cancer patients. ${ }^{41}$ However, the short time period between diagnosis and treatment, and the lack of training in this field by dental professionals, are among the barriers to be overcome in the implementation of this proactive approach. ${ }^{42}$

Despite the aforementioned poor oral health conditions of the elderly, this is often not matched by their self-perception of oral health. Hence, it is vital to go beyond clinical aspects in planning the dental treatment of this age group.

\section{Oral health and general health in the elderly}

During the past 2 decades, various epidemiological studies have evaluated the association between oral infections (especially periodontitis) and systemic diseases. ${ }^{43,44}$ Although the data have not been conclusive, there is some scientific evidence to support the proposition that local periodontal infection may be an independent risk factor for certain diseases, including diabetes, cardiovascular disease, dementia, pulmonary infections, some types of cancer, kidney disease, erectile dysfunction, and preterm low-weight birth. ${ }^{45}$ Given the elevated prevalence of some of these conditions among the elderly, greater understanding is required of the interaction between oral disease and systemic chronic diseases to prevent their onset or worsening. ${ }^{46}$

Periodontal inflammation begins with the action of periodontopathogenic bacteria on the gingival sulcus, clinically developing from a simple reversible gingivitis to alveolar bone destruction, with consequent tooth mobility and loss or extraction. ${ }^{44}$ The local response of the host to these pathogens results in the formation of an intense inflammatory infiltrate. ${ }^{47}$ In the most aggressive cases, this inflammatory process culminates with ulceration of the periodontal pocket epithelium, providing an entry point for the systemic circulation of oral microorganisms, bacterial endotoxins, bacterial antigens, and proinflammatory mediators. ${ }^{44}$ Regardless of the underlying mechanism, the consequent systemic host response would explain the association between periodontitis and systemic diseases reported by some studies, although results have not yet proved conclusive. ${ }^{48}$ The most widely proposed mechanisms are: 1) inflammatory mechanisms, by which inflammation derived from the host immune response against periodontal pathogens originates molecules that gain access to the circulatory system, producing systemic inflammation with vascular and other repercussions; 2) bacterial mechanisms, by which bacteria or bacterial products directly invade the tissues of the organism; and 3) vascular mechanisms, activated by the presence in the systemic circulation of periodontal pathogens, causing platelet aggregation and atheroma/small thrombus formation. ${ }^{45}$

The biological relationship between diabetes and periodontal disease is well known. ${ }^{49}$ Meta-analyses have shown that oral hygiene and periodontal disease severity are worse in diabetics than in nondiabetics, but that there is no difference in the extent of periodontal disease. ${ }^{50}$ It was also reported that periodontal therapy with antibiotics reduced blood glucose in patients with type 2 diabetes. ${ }^{51}$ Conversely, poor glycemic control contributes to a worse periodontal condition, evidencing the interrelationship between periodontal disease and diabetes. ${ }^{51}$

Since 1989, when Mattila et $\mathrm{al}^{52}$ published the first evidence of an association between dental infection and advanced coronary atherosclerosis, this relationship has been widely supported by systematic reviews and meta-analyses and accepted by scientific societies. ${ }^{48,53}$ There is consistent and strong epidemiologic evidence that periodontitis increases the risk of future cardiovascular disease, but intervention trials are required to draw further conclusions. ${ }^{48,53}$ Recommendations for older adults to maintain adequate hygiene levels in order to prevent the onset or worsening of periodontal disease cannot be solely based on the association between this disease and ischemic cardiovascular disease.

Finally, the possibility that periodontitis is a risk factor for dementia and/or cognitive impairment has also been investigated, supported by the theories and evidence on the relationship between periodontitis and cardiovascular disease.$^{54-56}$ The role of local/systemic inflammation of periodontal origin in the pathogenesis of Alzheimer's disease (AD) is not fully understood, but there is considerable scientific evidence of its possible implication in the vascular damage. The systemic presence of inflammation factors derived from local inflammation in moderate-severe periodontal disease (eg, interleukin-1 $\beta$, interleukin-6, tumor necrosis factor- $\alpha$, and C-reactive protein, etc) has been implicated in brain inflammation and subsequent neurodegeneration in $\mathrm{AD}$ patients. ${ }^{57}$ An association has also been found between some serum antibodies against common periodontal organisms and cognitive impairment, ${ }^{54,58}$ and at least one interventional study reported an improvement in endothelial function after periodontal treatment. ${ }^{59}$ Although there is no definitive proof of a causal relationship between periodontal disease and AD or dementia, optimal periodontal health should be maintained in the elderly, not only due to the possible involvement in dementia, but also to maintain sufficient teeth for adequate nutrition and comfort. 
This problem is especially important in terminal stages of neurodegenerative disease, when the collaboration of patients is minimal and dental treatment requires deep sedation or general anesthesia.

\section{Impact of oral health on mastication and nutrition}

Two key public health objectives for the elderly are known as "healthy active aging" and "compression of morbidity", designed to delay physical deterioration as long as possible. Among the multiple approaches required to pursue this aim, the achievement of optimal nutritional intake is an important element and fundamental for the preservation of general health. ${ }^{60}$ The physical, physiological, psychosocial, and emotional characteristics of the elderly identify them as a population group at high risk of poor nutrition. Their diets are frequently monotonous, with a low energy and nutrient content and deficiencies in calcium, zinc, magnesium, iron, vitamin D, vitamin B6, vitamin B12, vitamin E, thiamin, retinol, carotenes, and folic acid. ${ }^{61}$ Disorders in the sensory perception of foods and changes in the hormones and neurotransmitters involved in satiety can contribute to the so-called "anorexia of aging". ${ }^{62}$ Physical factors influencing the nutritional state of the elderly include sensory alterations, reduced thirst, general deterioration of physiological functions, body composition changes, chronic diseases (including depressive states, strongly associated with malnutrition), polymedication, constipation, disability, or reduced physical activity. ${ }^{63}$ Poor oral health status is one of the most frequent causes of malnutrition due to its effect on mastication and swallowing, which can lead to severe deficiencies in energy and nutrient intake. ${ }^{64}$

As reported earlier, there is abundant scientific evidence to support the involvement of oral health in general health. Some authors have described the role of oral health in nutrition and, indirectly, in the control of different acute and chronic diseases. ${ }^{65}$ From a theoretical viewpoint, given that oral health is a modifiable risk factor, its improvement would reduce the risk of mastication and swallowing problems and the nutritional deficiencies they can cause. Deficient mastication is related to tooth loss, a lack of saliva, mastication force, and malocclusion problems. ${ }^{65}$ Some local studies have indicated that individuals with mastication problems avoid fresh fruits and vegetables, "well-done" meat, and even bread, ${ }^{66}$ preferring soft, easily chewable food that can often raise sugar and fat consumption to levels above recommendations, increasing their risk of cardiovascular diseases and metabolic syndrome. ${ }^{67}$

Two major epidemiological studies on nutrition and general health in over-65-year-olds in the United Kingdom (UK
National Diet and Nutrition Survey [NDNS] $)^{65}$ and the US (US National Health and Nutritional Examination Surveys [NHANES] $)^{68,69}$ demonstrated an inverse relationship between poor dental state and adequate dietary intake, with edentulism being a clear risk factor. They reported that the fact of being toothless, with or without prosthesis, limited the consumption of fruits and vegetables in the general adult population and in less favored social strata due to mastication problems. A decreased intake of proteins and most micronutrients, as well as an increased carbohydrate intake, were observed in individuals with fewer than 21 teeth. ${ }^{69}$ However, malnutrition risk is influenced by multiple factors besides dental status, including the general state of health, degree of dependence, socioeconomic status, and diet. ${ }^{70}$ Most published studies have failed to demonstrate that prosthetic rehabilitation alone improves the nutritional status of the elderly or modifies their dietary habits, ${ }^{70,71}$ although positive results were reported in some types of patients with certain types of prostheses. ${ }^{72}$ Other authors have promoted the combination of prosthetic treatment with dietary counseling. ${ }^{73}$ Further research is warranted on this issue.

A deficient food intake does not always produce a nutritional deficit. It has been reported that food mastication difficulties have a greater impact on the individual's quality of life than on his or her nutrition status. ${ }^{74} \mathrm{~A}$ study by our group $^{75}$ in an institutionalized elderly population found a strong association between oral quality of life and malnutrition risk, as measured with the Mini Nutritional Assessment. However, extrapolation of the results in the institutionalized elderly to the general elderly population is limited. The diet is usually determined by the institutions, which generally offer a well-balanced food intake and the blending of foods whose mastication is problematic. Malnutrition risk is greater in the noninstitutionalized elderly, especially those who live alone and require domiciliary care. ${ }^{76}$

Malnutrition in the elderly has also been associated with swallowing problems, mainly due to poor mastication, a lack of saliva and, occasionally, organic causes. ${ }^{77}$ The main recommendation is to modify the consistency of the diet, eliminating certain foods and reducing the possibility of nutritional deficit. ${ }^{78}$ However, the widespread practice of mashing/blending food can reduce its appeal, taste, and even its calorie, protein, and liquid content. ${ }^{79,80}$

\section{Conclusion}

In summary, the oral health status of the geriatric population is generally deficient, with an elevated prevalence of caries, periodontal disease, and tooth loss. These are responsible for mastication difficulties, chronic disease destabilization, and 
impairment of oral quality of life, with direct effects on the individual's general quality of life and well-being. Surveillance and improvement of the oral health of the elderly should be a key objective of the multidisciplinary team responsible for their care, including dentists, dental hygienists, geriatricians, and caregivers.

\section{Disclosure}

The authors report no conflicts of interest in this work.

\section{References}

1. World Health Organization. Constitution of the World Health Organization. Geneva, Switzerland: World Health Organization; 2006. Available from: http://www.who.int/governance/eb/who_constitution_en.pdf. Accessed January 18, 2011.

2. Whitehead M. The concepts and principles of equity and health. Int $J$ Health Serv. 1992;22(3):429-445.

3. Naito M, Yuasa H, Nomura Y, Nakayama T, Hamajima N, Hanada N. Oral health status and health-related quality of life: a systematic review. J Oral Sci. 2006;48(1):1-7.

4. Sischo L, Broder HL. Oral health-related quality of life: what, why, how, and future implications. J Dent Res. 2011;90(11):1264-1270.

5. Rogers SN. Quality of life for head and neck cancer patients - has treatment planning altered? Oral Oncol. 2009;45(4-5):435-439.

6. Brennan DS, Singh KA. General health and oral health self-ratings, and impact of oral problems among older adults. Eur J Oral Sci. 2011; 119(6):469-473.

7. Gerritsen AE, Allen PF, Witter DJ, Bronkhorst EM, Creugers NH. Tooth loss and oral health-related quality of life: a systematic review and meta-analysis. Health Qual Life Outcomes. 2010;8:126.

8. Willumsen T, Fjaera B, Eide H. Oral health-related quality of life in patients receiving home-care nursing: associations with aspects of dental status and xerostomia. Gerodontology. 2010;27(4):251-257.

9. Locker D, Matear D, Stephens M, Jokovic A. Oral health-related quality of life of a population of medically compromised elderly people. Community Dent Health. 2002;19(2):90-97.

10. Kandelman D, Petersen PE, Ueda H. Oral health, general health, and quality of life in older people. Spec Care Dentist. 2008;28(6): 224-236.

11. Yoon HS, Kim HY, Patton LL, Chun JH, Bae KH, Lee MO. Happiness, subjective and objective oral health status, and oral health behaviors among Korean elders. Community Dent Oral Epidemiol. 2013;41(5): 459-465.

12. Misumi S, Nakamoto T, Kondo Y, Mukaibo T, Masaki C, Hosokawa R. A prospective study of changes in oral health-related quality of life during immediate function implant procedures for edentulous individuals. Clin Oral Implants Res. Epub 2014 Mar 26.

13. Kuo HC, Kuo YS, Lee IC, Wang JC, Yang YH. The association of responsiveness in oral and general health-related quality of life with patients' satisfaction of new complete dentures. Qual Life Res. 2013;22(7):1665-1674.

14. Locker D, Allen F. What do measures of 'oral health-related quality of life' measure? Community Dent Oral Epidemiol. 2007;35(6):401-411.

15. Higginson IJ, Carr AJ. Measuring quality of life: using quality of life measures in the clinical setting. BMJ. 2001;322(7297):1297-1300.

16. Petersen PE, Kandelman D, Arpin S, Ogawa H. Global oral health of older people - call for public health action. Community Dent Health. 2010;27(4 Suppl 2):257-267.

17. Murray Thomson W. Epidemiology of oral health conditions in older people. Gerodontology. 2014;31 Suppl 1:9-16.

18. Wyatt CC, Wang D, Aleksejuniene J. Incidence of dental caries among susceptible community-dwelling older adults using fluoride toothpaste: 2-year follow-up study. J Can Dent Assoc. 2014;80:e44.
19. Thomson WM. Dental caries experience in older people over time: what can the large cohort studies tell us? Br Dent J. 2004;196(2):89-92; discussion 87.

20. Hayes M, Allen E, da Mata C, McKenna G, Burke F. Minimal intervention dentistry and older patients part 2: minimally invasive operative interventions. Dent Update. 2014;41(6):500-502, 504-505.

21. Hirotomi T, Yoshihara A, Yano M, Ando Y, Miyazaki H. Longitudinal study on periodontal conditions in healthy elderly people in Japan. Community Dent Oral Epidemiol. 2002;30(6):409-417.

22. Kassebaum NJ, Bernabé E, Dahiya M, Bhandari B, Murray CJ, Marcenes W. Global burden of severe periodontitis in 1990-2010: a systematic review and meta-regression. J Dent Res. 2014;93(11):1045-1053.

23. Polzer I, Schwahn C, Völzke H, Mundt T, Biffar R. The association of tooth loss with all-cause and circulatory mortality. Is there a benefit of replaced teeth? A systematic review and meta-analysis. Clin Oral Investig. 2012;16(2):333-351.

24. Brown DW. Complete edentulism prior to the age of 65 years is associated with all-cause mortality. J Public Health Dent. 2009;69(4):260-266.

25. Emami E, de Souza RF, Kabawat M, Feine JS. The impact of edentulism on oral and general health. Int J Dent. 2013;2013:498305.

26. Dye BA, Li X, Thorton-Evans G. Oral health disparities as determined by selected healthy people 2020 oral health objectives for the United States, 2009-2010. NCHS Data Brief. 2012;(104):1-8.

27. Ministry of Health. Our Oral Health: Key Findings of the 2009 New Zealand Oral Health Survey. Wellington, New Zealand: Ministry of Health; 2010.

28. Osterberg T, Carlsson GE. Dental state, prosthodontic treatment and chewing ability - a study of five cohorts of 70-year-old subjects. J Oral Rehabil. 2007;34(8):553-559.

29. Kassebaum NJ, Bernabé E, Dahiya M, Bhandari B, Murray CJ, Marcenes W. Global burden of severe tooth loss: a systematic review and meta-analysis. $J$ Dent Res. 2014;93(7 suppl):20S-28S.

30. Shinsho F. New strategy for better geriatric oral health in Japan: 80/20 movement and Healthy Japan 21. Int Dent J. 2001;51(3 Suppl):200-206.

31. Käyser AF. How much reduction of the dental arch is functionally acceptable for the ageing patient? Int Dent J. 1990;40(3):183-188.

32. Singh ML, Papas A. Oral implications of polypharmacy in the elderly. Dent Clin North Am. 2014;58(4):783-796.

33. Scully C. Drug effects on salivary glands: dry mouth. Oral Dis. 2003; 9(4):165-176.

34. Mortazavi H, Baharvand M, Movahhedian A, Mohammadi M, Khodadoustan A. Xerostomia due to systemic disease: a review of 20 conditions and mechanisms. Ann Med Health Sci Res. 2014;4(4):503-510.

35. Hahnel S, Schwarz S, Zeman F, Schäfer L, Behr M. Prevalence of xerostomia and hyposalivation and their association with quality of life in elderly patients in dependence on dental status and prosthetic rehabilitation: a pilot study. J Dent. 2014;42(6):664-670.

36. Porter SR, Scully C, Hegarty AM. An update of the etiology and management of xerostomia. Oral Surg Oral Med Oral Pathol Oral Radiol Endod. 2004;97(1):28-46.

37. Plemons JM, Al-Hashimi I, Marek CL; American Dental Association Council on Scientific Affairs. Managing xerostomia and salivary gland hypofunction: executive summary of a report from the American Dental Association Council on Scientific Affairs. J Am Dent Assoc. 2014;145(8): 867-873.

38. Petersen PE, Bourgeois D, Ogawa H, Estupinan-Day S, Ndiaye C. The global burden of oral diseases and risk to oral health. Bull World Health Organ. 2005;83(9):661-669.

39. Petersen PE. The World Oral Health Report 2003: continuous improvement of oral health in the 21st century - the approach of the WHO Global Oral Health Programme. Community Dent Oral Epidemiol. 2003;31 Suppl 1:3-23.

40. Torres-Carranza E, Infante-Cossío P, Hernández-Guisado JM, HensAumente E, Gutierrez-Pérez JL. Assessment of quality of life in oral cancer. Med Oral Patol Oral Cir Bucal. 2008;13(11):E735-E741.

41. Rogers SN. Quality of life perspectives in patients with oral cancer. Oral Oncol. 2010;46(6):445-447. 
42. Patel Y, Bahlhorn H, Zafar S, Zwetchkenbaum S, Eisbruch A, MurdochKinch CA. Survey of Michigan dentists and radiation oncologists on oral care of patients undergoing head and neck radiation therapy. J Mich Dent Assoc. 2012;94(7):34-45.

43. Cullinan MP, Seymour GJ. Periodontal disease and systemic illness: will the evidence ever be enough? Periodontol 2000. 2013;62(1):271-286.

44. Otomo-Corgel J, Pucher JJ, Rethman MP, Reynolds MA. State of the science: chronic periodontitis and systemic health. J Evid Based Dent Pract. 2012;12(3 Suppl):20-28.

45. Meurman JH, Sanz M, Janket SJ. Oral health, atherosclerosis, and cardiovascular disease. Crit Rev Oral Biol Med. 2004;15(6):403-413.

46. Tavares M, Lindefjeld Calabi KA, San Martin L. Systemic diseases and oral health. Dent Clin North Am. 2014;58(4):797-814.

47. Mustapha IZ, Debrey S, Oladubu M, Ugarte R. Markers of systemic bacterial exposure in periodontal disease and cardiovascular disease risk: a systematic review and meta-analysis. J Periodontol. 2007;78(12): 2289-2302.

48. Friedewald VE, Kornman KS, Beck JD, et al; American Journal of Cardiology; Journal of Periodontology. The American Journal of Cardiology and Journal of Periodontology Editors' Consensus: periodontitis and atherosclerotic cardiovascular disease. Am J Cardiol. 2009;104(1):59-68.

49. Wolff LF. Diabetes and periodontal disease. Am J Dent. 2014;27(3): 127-128.

50. Khader YS, Dauod AS, El-Qaderi SS, Alkafajei A, Batayha WQ. Periodontal status of diabetics compared with nondiabetics: a meta-analysis. J Diabetes Complications. 2006;20(1):59-68.

51. Lalla E, Papapanou PN. Diabetes mellitus and periodontitis: a tale of two common interrelated diseases. Nat Rev Endocrinol. 2011;7(12): 738-748.

52. Mattila KJ, Nieminen MS, Valtonen VV, et al. Association between dental health and acute myocardial infarction. BMJ. 1989;298(6676):779-781.

53. Tonetti MS, Van Dyke TE; working group 1 of the joint EFP/AAP workshop. Periodontitis and atherosclerotic cardiovascular disease: consensus report of the Joint EFP/AAP Workshop on Periodontitis and Systemic Diseases. J Periodontol. 2013;84(4 Suppl):S24-S29.

54. Noble JM, Scarmeas N, Papapanou PN. Poor oral health as a chronic, potentially modifiable dementia risk factor: review of the literature. Curr Neurol Neurosci Rep. 2013;13(10):384.

55. Noble JM, Borrell LN, Papapanou PN, Elkind MS, Scarmeas N, WrightCB. Periodontitis is associated with cognitive impairment among older adults: analysis of NHANES-III. J Neurol Neurosurg Psychiatry. 2009; 80(11):1206-1211.

56. Kaye EK, Valencia A, Baba N, Spiro A, Dietrich T, Garcia RI. Tooth loss and periodontal disease predict poor cognitive function in older men. J Am Geriatr Soc. 2010;58(4):713-718.

57. Kamer AR, Morse DE, Holm-Pedersen P, Mortensen EL, Avlund K. Periodontal inflammation in relation to cognitive function in an older adult Danish population. J Alzheimers Dis. 2012;28(3):613-624.

58. Sparks Stein P, Steffen MJ, Smith C, et al. Serum antibodies to periodontal pathogens are a risk factor for Alzheimer's disease. Alzheimers Dement. 2012;8(3):196-203.

59. Tonetti MS, D'Aiuto F, Nibali L, et al. Treatment of periodontitis and endothelial function. $N$ Engl J Med. 2007;356(9):911-920.

60. Bidlack WR. Interrelationships of food, nutrition, diet and health: the National Association of State Universities and Land Grant Colleges White Paper. J Am Coll Nutr. 1996;15(5):422-433.
61. Montgomery SC, Streit SM, Beebe ML, Maxwell PJ 4th. Micronutrient needs of the elderly. Nutr Clin Pract. 2014;29(4):435-444.

62. Martone AM, Onder G, Vetrano DL, et al. Anorexia of aging: a modifiable risk factor for frailty. Nutrients. 2013;5(10):4126-4133.

63. Ahmed T, Haboubi N. Assessment and management of nutrition in older people and its importance to health. Clin Interv Aging. 2010;5:207-216.

64. Sheiham A, Steele J. Does the condition of the mouth and teeth affect the ability to eat certain foods, nutrient and dietary intake and nutritional status amongst older people? Public Health Nutr. 2001;4(3):797-803.

65. Sheiham A, Steele JG, Marcenes W, et al. The relationship among dental status, nutrient intake, and nutritional status in older people. J Dent Res. 2001;80(2):408-413.

66. Hung HC, Colditz G, Joshipura KJ. The association between tooth loss and the self-reported intake of selected CVD-related nutrients and foods among US women. Community Dent Oral Epidemiol. 2005;33(3):167-173.

67. Friedlander AH, Weinreb J, Friedlander I, Yagiela JA. Metabolic syndrome: pathogenesis, medical care and dental implications. J Am Dent Assoc. 2007;138(2):179-187; quiz 248.

68. Nowjack-Raymer RE, Sheiham A. Numbers of natural teeth, diet, and nutritional status in US adults. J Dent Res. 2007;86(12):1171-1175.

69. Zhu Y, Hollis JH. Tooth loss and its association with dietary intake and diet quality in American adults. J Dent. 2014;42(11):1428-1435.

70. Wöstmann B, Michel K, Brinkert B, Melchheier-Weskott A, Rehmann P, Balkenhol M. Influence of denture improvement on the nutritional status and quality of life of geriatric patients. J Dent. 2008;36(10):816-821.

71. Moynihan PJ, Butler TJ, Thomason JM, Jepson NJ. Nutrient intake in partially dentate patients: the effect of prosthetic rehabilitation. J Dent. 2000;28(8):557-563.

72. Morais JA, Heydecke G, Pawliuk J, Lund JP, Feine JS. The effects of mandibular two-implant overdentures on nutrition in elderly edentulous individuals. J Dent Res. 2003;82(1):53-58.

73. Bradbury J, Thomason JM, Jepson NJ, Walls AW, Allen PF, Moynihan PJ. Nutrition counseling increases fruit and vegetable intake in the edentulous. J Dent Res. 2006;85(5):463-468.

74. Moynihan P, Thomason M, Walls A, et al. Researching the impact of oral health on diet and nutritional status: methodological issues. J Dent. 2009;37(4):237-249.

75. Gil-Montoya JA, Ponce G, Sánchez Lara I, Barrios R, Llodra JC, Bravo M. Association of the oral health impact profile with malnutrition risk in Spanish elders. Arch Gerontol Geriatr. 2013;57(3):398-402.

76. Cuervo M, García A, Ansorena D, et al. Nutritional assessment interpretation on 22,007 Spanish community-dwelling elders through the Mini Nutritional Assessment test. Public Health Nutr. 2009;12(1):82-90.

77. Lieu PK, Chong MS, Seshadri R. The impact of swallowing disorders in the elderly. Ann Acad Med Singapore. 2001;30(2):148-154.

78. Garcia JM, Chambers E 4th. Managing dysphagia through diet modifications. Am J Nurs. 2010;110(11):26-33; quiz 34-35.

79. Wright L, Cotter D, Hickson M, Frost G. Comparison of energy and protein intakes of older people consuming a texture modified diet with a normal hospital diet. J Hum Nutr Diet. 2005;18(3):213-219.

80. Whelan K. Inadequate fluid intakes in dysphagic acute stroke. Clin Nutr. 2001;20(5):423-428.
Clinical Interventions in Aging

\section{Publish your work in this journal}

Clinical Interventions in Aging is an international, peer-reviewed journal focusing on evidence-based reports on the value or lack thereof of treatments intended to prevent or delay the onset of maladaptive correlates of aging in human beings. This journal is indexed on PubMed Central, MedLine,

\section{Dovepress}

CAS, Scopus and the Elsevier Bibliographic databases. The manuscript management system is completely online and includes a very quick and fair peer-review system, which is all easy to use. Visit http://www.dovepress. com/testimonials.php to read real quotes from published authors. 